\title{
ALECRIM (Rosmarinus officinalis L.): PROPRIEDADES ANTIMICROBIANA E QUÍMICA DO ÓLEO ESSENCIAL
}

\author{
ALEXANDRE PORTE * \\ RONOEL LUIZ DE OLIVEIRA GODOY **
}

\begin{abstract}
Apresenta breve revisão bibliográfica sobre a composição química e as propriedades antimicrobianas do óleo essencial de alecrim. Enfoca aspectos gerais, usos, atividade contra bactérias e fungos em alimentos e as principais substâncias do óleo de alecrim oriundo de diferentes países. Conclui que os compostos oxigenados são os responsáveis pelas atividades fisiológica e antimicrobiana, mas há discordância sobre os compostos majoritários, ora hidrocarbonetos ora oxigenados.
\end{abstract}

PALAVRAS-CHAVE: ALECRIM; ÓLEO DE ALECRIM; PROPRIEDADES ANTIMICROBIANAS; PROPRIEDADES QUÍMICAS; ÓLEO ESSENCIAL.

\section{INTRODUÇÃO}

As ervas e condimentos (entre os quais o alecrim) são estudados há mais de um século em todo o mundo, a fim de elucidar os compostos químicos responsáveis pelos efeitos fisiológicos e atividade contra microrganismos, bem como os mecanismos pelos quais estes efeitos são manifestados. Apesar disso, ainda existem divergências nos resultados relatados na literatura, tornando o estudo da composição química dos óleos essenciais de grande importância.

O presente trabalho teve por objetivo relatar e comparar a composição química de mais de 50 óleos essenciais de alecrim, estudados em todo o mundo, ressaltando as classes dos compostos majoritários e aqueles aos quais têm sido atribuídas atividades fisiológica e antimicrobiana.

* Nutricionista, Doutorando em Ciências, Universidade Federal do Rio de Janeiro

(UFRJ), Rio de Janeiro, RJ. (e-mail: alexandrepor@zipmail.com.br).

** D.Sc., Pesquisador III, Embrapa Agroindústria de Alimentos, Guaratiba, RJ. 


\section{ASPECTOS GERAIS E APLICAÇÕES}

O Rosmarinus officinalis $L$., pertencente à família Lamiaceae, é um arbusto perene, nativo do Mediterrâneo, que atinge até 1,5 m de altura (1-4).

A família Lamiaceae compreende 150 gêneros com cerca de 2800 espécies distribuídas em todo o mundo, sendo o maior centro de dispersão a região do Mediterrâneo (5-7). Muitas das espécies introduzidas no Brasil são plantas medicinais e produtoras de óleos essenciais, sendo utilizadas também como condimentos ou como flores ornamentais (7). Dentre os gêneros cultivados destacam-se várias espécies usadas como condimentos, tais como: erva-cravo (Hypttis), alfavaca (Ocimum), alecrim (Rosmarinus), hortelã-pimenta (Mentha), manjericão (Origanum), manjerona (Majorana), basilicão (Basilicum), orégano (Origanum), tomilho (Thymus) e erva-cidreira (Melissa). Outras são cultivadas como flores ornamentais ou para produção de óleo essencial, como: sálvia (Salvia), alfazema (Lavandula) e patchuli (Pogostemum) (5). A espécie Salvia officinalis e mais algumas, como $S$. triloba e $S$. lavandulaefolia também são usadas como condimentos.

De nome popular alecrim, $R$. officinalis apresenta diversos outros sinônimos: alecrim-de-cheiro, alecrim-das-hortas, alecrim-da-casa, alecrim-comum, alecrim-verdadeiro, rosmaninho (1). Ocupava lugar de honra entre as plantas domésticas trazidas pelos primeiros colonos (2). Seus principais produtores são a Itália, lugoslávia, Espanha, Grécia, Turquia, França, Portugal, Egito e norte da África (3-4). Pode produzir flores azuis ou brancas e seu nome em latim significa "orvalho do mar", referindo-se ao local de origem desta planta $(1,3,7)$. Apresenta emprego culinário, medicinal, farmacêutico e cosmético $(3,8)$. Proporciona um dos aromas mais refrescantes e menos caros, sendo uma das ervas mais importantes da atualidade (9). Existem lendas e tradições a respeito desta planta. Supunha-se que só crescia no jardim dos justos e tinha fama de reforçar a memória, por isso converteu-se no símbolo da fidelidade, da amizade e da lembrança. Quando faltava incenso nas igrejas, o alecrim era queimado como substituto. Os estudantes gregos usavam-no com freqüência durante as provas, pois acreditavam em seu poder de reforçar o cérebro e a memória. Isto se deve à dilatação dos tecidos que a planta provoca, aumentando sua irrigação e exercendo efeito estimulante (3). É uma das primeiras espécies identificadas e classificadas da família Lamiaceae. Conhecida desde 116-27 a.C., apresenta propriedades estomacais, estimulantes, antiespasmódica e emenagogas. As velhas parteiras européias polvilhavam o pó das folhas sobre o cordão umbilical dos recém-nascidos, por considerá-lo cicatrizante (1). As flores apresentam 
propriedades estomacais, estimulantes, emenagogas e abortivas. Os ramos perfumam e evitam a traça nas roupas. Excelente planta melífera transmite ao mel sabor especial (1-2).

O alecrim apresenta gosto agridoce, sendo usado em pães, preparações que contenham carne e para adornar saladas (10). Também é empregado em batatas fritas, caldos verdes, sobremesas, biscoitos, geléias, saladas de frutas, marmeladas e vinhos quentes (3). Nos Estados Unidos é utilizado em carnes, aves, peixes e lingüiças (11) e no Marrocos é adicionado à manteiga e a outros alimentos para aumentar a vida-de-prateleira dos produtos (12).

Vários trabalhos têm sido publicados em relação ao isolamento e identificação de diferentes antioxidantes, diterpenos e triterpenos, bem como flavonóides de Rosmarinus officinalis (13). Na verdade, o alecrim e a sálvia são dois dos condimentos antioxidantes mais potentes, sobretudo, em banha de porco (14). As propriedades antioxidantes do extrato de alecrim têm recebido considerável atenção nos últimos anos, sendo reconhecidas desde a Antiguidade. Mais recentemente, tentativas têm sido realizadas para determinar a estrutura química dos constituintes ativos do vegetal, sendo que, rosmanol e os diterpenos rosmaridifenol e rosmariquinona já foram identificados (4).

Os efeitos antioxidativos de rosmaridifenol e rosmariquinona em banha foram superiores ao hidroxianisol butilado (BHA) e semelhante ao hidroxitolueno butilado (BHT). O BHA e o BHT são poderosos antioxidantes sintéticos empregados na indústria de alimentos, mas acredita-se que apresentem atividade carcinogênica. Por isso, sua substituição por antioxidantes contidos em condimentos é de grande interesse (14-15). Infelizmente, várias substâncias com propriedades antioxidativas como o timol (do tomilho), a tujona (da sálvia) e o eugenol (do cravo) também apresentam forte caráter aromático, limitando seus usos em alimentos (14).

A atividade antioxidativa de condimentos se deve a diterpenos fenólicos (16-18). Além do rosmaridifenol e rosmariquinona, também são encontrados no alecrim: epirosmanol, isorosmanol e ácido rosmarínico, em pequenas quantidades. Os principais componentes antioxidantes do alecrim e da sálvia, contudo, são os diterpenos fenólicos carnosol e o ácido carnósico (14). O ácido carnósico mostrou-se estável à luz por 5 horas, mas degradase na presença de oxigênio, formando carnosol, e deste, rosmanol e epirosmanol (17). A atividade antioxidativa do ácido carnósico é superior à do carnosol, todavia o ácido é bastante instável, sendo oxidado ao 
carnosol. O carnosol apresenta a vantagem de ser uma lactona fenólica diterpênica inodora e insípida, o que permite sua aplicação em alimentos. Alecrim em níveis de $0,05 \%$ em alimentos foram aceitos pelos consumidores (14).

O alecrim e seus extratos são os únicos condimentos usados comercialmente como antioxidantes, sendo alguns combinados com tocoferóis. Isto porque, existe sinergismo entre o alecrim e o $\alpha$-tocoferol (extrato de alecrim regenera o tocoferol). $\mathrm{O}$ alecrim também demonstra efeito sinérgico com ácido cítrico e $\mathrm{BHA}$, mas não com ácido ascórbico (14).

O aquecimento resulta em alguma redução da atividade antioxidante da maioria dos condimentos, devido à reação dos compostos fenólicos com outras substâncias (14).

\section{O ÓLEO ESSENCIAL}

A família Lamiaceae engloba diversas plantas aromáticas, das quais é possível extrair óleo essencial muito cheiroso, que apresenta em sua composição química, complexa mistura de hidrocarbonetos, álcoois e compostos carbonílicos.

É geralmente aceito que os óleos essenciais, secretados pelas glândulas capilares, ao cobrirem as folhas protegem a planta contra herbívoros e patógenos, enquanto o óleo secretado pelas glândulas capilares nas flores servem para atrair agentes polinizadores, no caso da família Lamiaceae, principalmente as abelhas (19).

Os óleos essenciais podem ser divididos em 2 grupos: aqueles obtidos pela compressão de frutas cítricas e os obtidos por destilação a vapor de materiais vegetais (como folhas e sementes) (20). A maior parte dos óleos essenciais de plantas condimentares são extraídos por diferentes técnicas de destilação a vapor, como destilação com vapor direto, indireto e coobação.

A composição dos óleos essenciais das plantas é determinada pela sua espécie e variedade e também por condições agronômicas, período de colheita e tipo de processamento. Muito importantes também são as características ambientais e ecológicas particulares da região de crescimento do vegetal. Estas fornecem características organolépticas 
como pungência, amargor e outras, de maneira particular e peculiar a cada planta aromática (8).

O óleo essencial do alecrim é incorporado em ungüentos para reumatismo, eczema, úlcera e feridas. Também é usado como rubefaciente, estimulante, inseticida e desodorante bucal. As folhas são empregadas em chás de ervas com ação carminativa, gástrica, abortiva e antiespasmódica. São misturadas com outras drogas para a prevenção de alopécia, estimulação do crescimento capilar e prevenção de caspa e oleosidade. A inalação ou ingestão do óleo estimula o Sistema Nervoso Central (13). Também foi atribuída atividade anticonvulsiva e hepatoprotetora ao vegetal (21).

\section{PROPRIEDADES ANTIMICROBIANAS DO ALECRIM E DE SEU ÓLEO ESSENCIAL}

Em óleos essenciais de alecrim, de diferentes partes do Egito, foi encontrada adequada atividade inibitória contra Candida albicans, Cryptococcus neoformans, Mycobacterium intracellularae, mas nenhuma atividade contra Staphylococcus aureus, Escherichia coli, Pseudomonas aeruginosas, Saccharomyces cerevisiae, Aspergillus flavus, Aspergillus fumigatus e Trichophyton mentagrophytes. A atividade relativamente alta contra fungos sugere uso potencial em tratamentos de meningite e em pneumonia causadas por $C$. neoformans, bem como para o tratamento de infecções cutâneas e diarréia provocadas por Candida albicans e para o tratamento de infecções sistêmicas causadas por Mycobactericum intracellularae em pacientes com AIDS. Os principais componentes que o óleo de alecrim egípcio apresentou foram: cânfora (14,9\%), $\alpha$-pineno $(9,3 \%)$ e 1,8 -cineol $(9,0 \%)(13)$.

A ação bactericida do alecrim contra Staphylococcus aureus em carnes tem sido muito citada (22). Foi observada alta sensibilidade de bactérias Gram positivas aos óleos essenciais de alecrim (borneol 26,5\%, $\alpha$-terpineno $15,6 \%$, $\alpha$-pineno $12,7 \%$ ) e sálvia (tujona $41,5 \%$, limoneno $14,7 \%$ ), provenientes do Egito, incluindo Sthaphylococcus aureus, Micrococcus $s p$. e Sarcina sp., bem como a levedura Saccharomyces cerevisiae. Entretanto, nenhum ou muito pouco efeito foi verificado contra as bactérias Gram negativas Pseudomonas fluorences, Escherichia coli e Serratia marcescens. Contra estas últimas, o tomilho (timol 42,7\%, p-cimeno $36,0 \%$ ) foi altamente ativo, assim como para as Gram positivas. Diversos autores acreditam que núcleos aromáticos, contendo um grupo funcional 
polar, sejam os responsáveis pela atividade antimicrobiana. O borneol (presente no alecrim) e a tujona (presente na sálvia) mostraram reduzido efeito inibitório, quando comparados ao timol (presente no tomilho), devido à ausência de compostos aromáticos (15) (Figura 1).

\section{FIGURA 1 - FÓRMULAS ESTRUTURAIS DE BORNEOL, TUJONA E TIMOL}

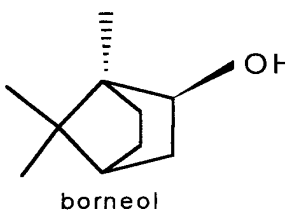

borneol

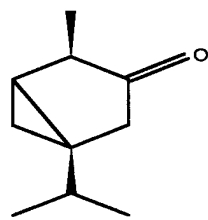

alfa-tujona<smiles>Cc1ccc(C(C)C)c(O)c1</smiles>

timol

Óleos essenciais de alecrim, sálvia e tomilho egípcios foram testados contra o crescimento de Bacillus subtilis e Staphylococcus aureus, e o óleo de alecrim mostrou-se menos ativo quando comparado aos óleos essenciais de tomilho e de sálvia (23). Tal resultado diverge dos demais apresentados na literatura $(11,22)$. No entanto, o principal composto encontrado no óleo essencial de alecrim foi o $\alpha$-pineno $(36,4 \%)(23)$. Acredita-se que esta baixa atividade contra o crescimento bacteriano apresentado pelo óleo essencial de alecrim pode ser justificada pela presença majoritária de $\alpha$-pineno que é um hidrocarboneto monoterpênico sem núcleos aromáticos e grupos funcionais polares, ao qual é atribuído a atividade antimicrobiana.

A tentativa de alguns autores para hierarquizar a atividade antimicrobiana de óleos essenciais está apresentada no Quadro 1.

QUADRO 1 - ATIVIDADE ANTIMICROBIANA DE ÓLEOS ESSENCIAIS

\begin{tabular}{|c|}
\hline ORDEM DECRESCENTE DE ATIVIDADE ANTIMICROBIANA \\
\hline Fen is $>$ AEcoois $>$ alde dos $>$ cetonas $>$ xidos \\
ou \\
Fen is $<$ xidos $<$ hidrocarbonetos $<$ (6teres (25) \\
Fen is $>$ cetona $>$ xidos $(12)$
\end{tabular}


A atividade antibactericida de óleos essenciais de vários condimentos contra microrganismos deterioradores de carne foi testada. Verificou-se que, nas primeiras 24 horas, a extensão dos efeitos inibitórios em quatro bactérias Gram positivas (Brochothrix thermosphacta, Carnobacterium piscicola, Lactobacillus curvatus e Lactobacillus sake) e duas Gram negativas (Pseudomonas fluorences e Serratia liquefacienciens) foram os mesmos. Todavia, a partir de 48 horas as Gram negativas foram menos afetadas que as Gram positivas. Possivelmente, os lipopolissacarídios contidos na parede celular das Gram negativas evitem que os componentes atinjam a membrana citoplasmática e exerçam ação destruidora da célula. Dentre os oito óleos testados, três foram eficientes em diluições 1/100 por 48 horas (cravo, canela e alecrim) e o restante (tomilho, alho, orégano, pimenta-preta e cominho) foi eficaz apenas por 24 horas em diluições de $1 / 10$. Dos três óleos mais eficientes, dois exibiam significativas quantidades de eugenol, mas o alecrim não. Por isso, tais autores sugeriram que o efeito antimicrobiano do alecrim pode não ser devido à presença de uma única substância em grande quantidade, mas sim, ao efeito sinérgico de diversas substâncias em pequenas quantidades (24). Em contraste, a atividade antimicrobiana dos óleos essenciais foi relacionada com a de seus componentes majoritários, podendo também haver sinergismo entre alguns constituintes principais como hidrocarbonetos e álcoois (25).

De maneira geral, as bactérias Gram positivas são mais sensíveis aos condimentos que as Gram negativas $(11,26)$. Bacillus cereus e Sthaphylococcus aureus são exemplos (11), entretanto, existem exceções. L. monocytogenes, Gram positiva, foi mais resistente a 11 óleos essenciais que as bactérias Gram negativas ( $E$. Coli, Salmonella typhimuriume Vibrio vulnificus). Parece que a variabilidade da resistência das Gram positivas deve-se à diferença entre cepas da mesma espécie bacteriana (24). Vibrio parahaemolyticus, apesar de Gram negativo, foi altamente sensível à sálvia e alecrim (11).

Os meios pelos quais os microrganismos são inibidos por óleos essenciais parecem incluir diferentes modos de ação. As inibições mais freqüentes envolvem componentes fenólicos de óleos, os quais sensibilizam a bicamada lipídica da membrana celular e alteram a atividade dos canais de cálcio, causando aumento da permeabilidade e liberação dos constituintes intracelulares vitais (24, 26-28). Também podem ocorrer danos ao sistema enzimático do microrganismo envolvido na produção de energia e na síntese de componentes estruturais, bem como a destruição ou inativação de material genético (26). Os grupos hidroxilas fenólicos (como no timol) são bastante reativos e formam pontes de hidrogênio com sítios 
ativos de enzimas-alvo, inativando-as. Parece que o efeito indutivo do grupo isopropil deve ser considerado ao lado da aromaticidade da molécula (15).

Em geral, as células vegetativas são mais resistentes que os esporos aos óleos essenciais e os esporos de Bacilus cereus são mais sensíveis que os de Clostridium botulinum. Estas diferenças podem ser explicadas pela variação nos comportamentos hidrofóbicos. Os microrganismos mais hidrofóbicos são mais sensíveis aos óleos essenciais que os hidrofílicos. As células vegetativas são mais hidrofílicas, o que poderia exigir maior concentração de óleos essenciais para inibir o seu crescimento (25).

As concentrações de sálvia e alecrim, para exercerem os efeitos antibacterianos desejados, são maiores que as utilizadas habitualmente em alimentos para propósitos flavorizantes. Contudo, associados a outros agentes podem contribuir para o controle do crescimento bacteriano e evitar a rancificação de alimentos (11).

Queijos do tipo Cheddar foram cobertos com óleo de alecrim para retardar a deterioração por fungos Penicillium roquefor, Penicillium camembertie Aspergillus parasiticus. O óleo essencial de alecrim não foi eficiente para retardar a deterioração dos queijos Cheddar causada por $P$. roquefor, contudo inibiu o crescimento de $P$. camemberti e $A$. parasiticus. Infelizmente, as concentrações do óleo de alecrim necessárias para retardar a deterioração dos queijos tornaram os alimentos inaceitáveis na avaliação sensorial (29).

O Aspergillus parasiticus e o A. flavus produzem aflatoxinas como metabólitos em quantidades que variam conforme a composição química do substrato. As aflatoxinas são toxinas hepatocarcinógenas, mutagênicas e teratogênicas, sendo que sua inalação também pode trazer prejuízos à saúde. Deste modo, é desejável prevenir sua formação ou inativá-la em cereais, carnes, queijos, nozes e frutas. O óleo de alecrim a $2 \mathrm{mg} / \mathrm{mL}$ (borneol 26,5\%, $\gamma$-terpineno 15,6\%, $\alpha$-pineno 12,7\%, cariofileno 9,6\%) inibiu completamente a formação de aflatoxina por $A$. parasiticus e, de maneira geral, foi mais efetivo no controle do fungo que o óleo de sálvia (30-33).

\section{COMPOSIÇÃO QUÍMICA DO ÓLEO ESSENCIAL}

Diferentes cultivares de alecrim e diversas origens genéticas, associadas aos aspectos ambientais de crescimento particulares de cada região, ao 
tempo de colheita e o tipo de destilação influenciam a composição química e o rendimento dos óleos essenciais produzidos (4).

O Gráfico 1 apresenta os rendimentos obtidos em diversos países e as Tabelas 1 e 2 as principais substâncias encontradas nos óleos essenciais de alecrim, destacando-se em negrito, os compostos em concentrações superiores a $10 \%$.

\section{GRÁFICO 1 - COMPARAÇÃO ENTRE OS RENDIMENTOS DE ÓLEO ESSENCIAL DE ALECRIM DE DIFERENTES ORIGENS $(8,13,36,41,42,44,45)$}

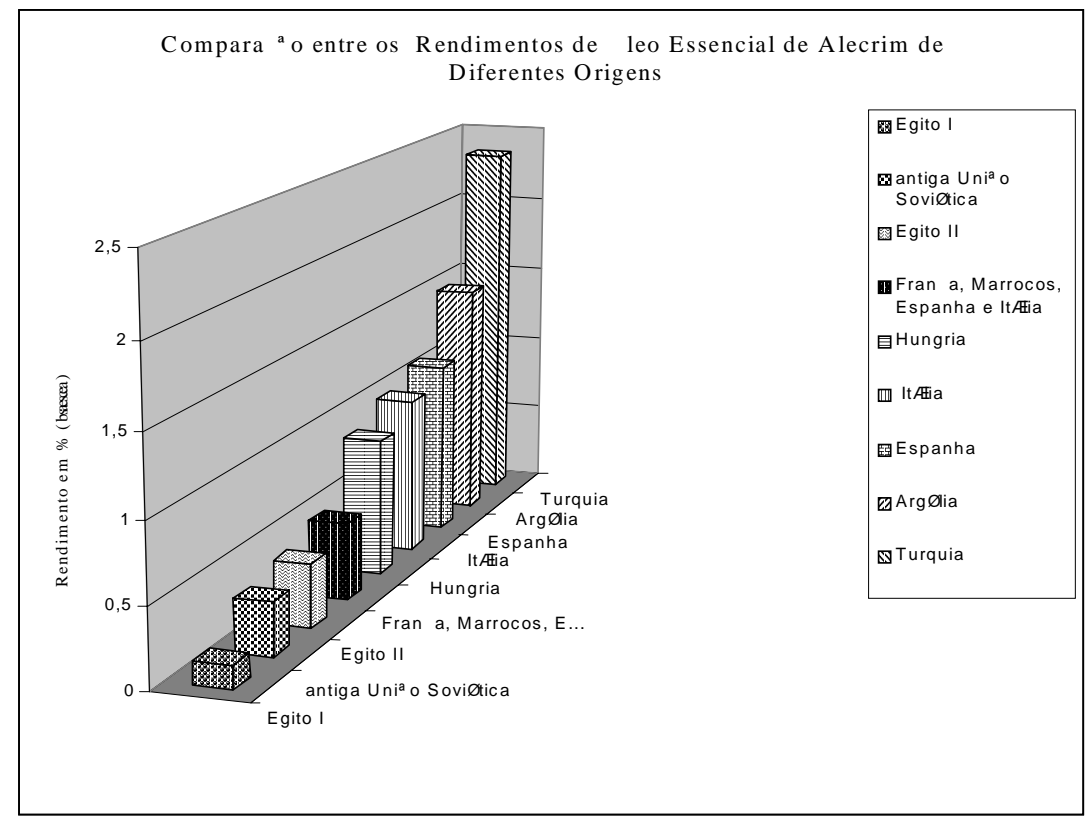

Estudos prévios do óleo essencial de Rosmarinus officinalis apresentaram como seus principais constituintes: 1,8-cineol, cânfora, borneol, acetato de bornila, canfeno, $\alpha$-pineno, $p$-cimeno, mirceno, sabineno, $\beta$-felandreno, $\beta$-pineno, dipenteno e $\beta$-cariofileno (13). Alguns componentes emprestam certas características específicas ao óleo essencial de alecrim, ou seja, 1,8-cineol - aroma refrescante; $\alpha$-pineno - aroma de pinho; cânfora aroma de menta; borneol - gosto acre (4). 


\section{TABELA 1 - COMPOSIÇÃO QUÍMICA PERCENTUAL DE ÓLEOS ESSENCIAIS DE $R$. officinalis ENCONTRADA NA EUROPA $(8,34-43)$}

\begin{tabular}{|c|c|c|c|c|c|c|c|}
\hline \multirow[t]{2}{*}{ SUBST' NCIAS* } & \multicolumn{7}{|c|}{ PA"SES / N MERO DE AMOSTRAS } \\
\hline & Espanha /13 & Fran a/7 & Iugosl/Æia/5 & Hungria/3 & Portugal/3 & Bulg/Eia/1 & Grøia/1 \\
\hline tricileno & $0,34-0,44$ & $0,24-0,41$ & & & & & \\
\hline$\alpha$-thujeno & $0,08-1,06$ & $0,08-0,40$ & & & & & \\
\hline$\alpha$-pineno & $11,56-24,50$ & $10,4-35,08$ & $12,30-25,00$ & $1,40-14,40$ & $0,90-25,10$ & 31,10 & 10,30 \\
\hline canfeno & $7,67-22,08$ & $3,60-8,35$ & $3,20-10,50$ & $0,70-4,40$ & $1,30-4,30$ & 9,20 & 4,00 \\
\hline sabineno & $0,00-2,93$ & $0,21-1,36$ & $\operatorname{tra} 0$ & & Tra o & & \\
\hline$\beta$-pineno & $0,70-5,80$ & $0,60-7,60$ & $0,70-3,70$ & 0,30-13,70 & $1,50-3,40$ & 5,90 & \\
\hline mirceno & $0,09-9,50$ & $1,40-5,70$ & $0,00-3,40$ & & $19,20-52,10$ & 8,00 & \\
\hline$\alpha$-felandreno & $0,10-4,45$ & 0,10 & $0,00-0,10$ & & $0,00-1,80$ & 2,60 & \\
\hline$\delta$-3-careno & $0,07-0,19$ & & & & & & \\
\hline$\alpha$-terpineno & $0,00-1,75$ & $0,30-0,70$ & $0,00-1,20$ & & $0,00-0,70$ & & \\
\hline$p$-cimeno & $1,29-5,74$ & $1,39-2,30$ & $0,00-1,90$ & $0,30-4,20$ & $2,40-6,00$ & & \\
\hline limoneno & $3,45-5,81$ & $2,10-7,80$ & $1,50-3,30$ & 4,80 & $2,40-10,60$ & 5,60 & 0,40 \\
\hline 1,8-cineol & $6,11-30,10$ & $5,30-49,20$ & $18,50-39,20$ & $11,2-46,40$ & $4,20-14,70$ & & 51,20 \\
\hline cis-ocimeno & $0,09-1,83$ & $0,00-0,05$ & & & & & \\
\hline trans-ocimeno & $0,02-0,38$ & $0,02-0,53$ & & & & & \\
\hline$\gamma$-terpineno & $0,00-2,06$ & $0,28-1,28$ & $0,30-0,67$ & & 1,80 & & \\
\hline $\begin{array}{l}\text { trans-sabineno } \\
\text { hidratado }\end{array}$ & & $0,09-0,12$ & & $1,00-14,30$ & & & \\
\hline linalol & $0,16-14,10$ & $0,70-17,30$ & $0,70-14,50$ & 5,80 & $0,40-17,30$ & & 0,40 \\
\hline thujone & 0,10 & 0,50 & 0,50 & & 0,50 & & \\
\hline c nfora & $0,10-32,33$ & $0,10-16,10$ & $0,60-16,70$ & $13,0-31,00$ & $0,20-5,00$ & 7,30 & 5,50 \\
\hline isoborneol & & $0,40-0,60$ & & & & & \\
\hline borneol & $1,55-6,92$ & $3,10-6,53$ & $0,00-9,20$ & $1,00-14,30$ & 3,00 & & 4,70 \\
\hline 4-terpineol & $0,39-1,74$ & $0,00-1,21$ & $0,10-1,80$ & & $1,70-6,80$ & & \\
\hline terpinoleno & $0,10-1,29$ & $0,57-0,78$ & $0,50-2,30$ & Tra o & 0,60 & & \\
\hline$\alpha$-terpineol & $0,00-2,71$ & $0,00-1,60$ & $0,00-2,30$ & 0,50 & 0,60 & & \\
\hline verbenona & $0,02-5,30$ & $0,00-5,08$ & & 0,80-11,00 & $0,00-1,80$ & & \\
\hline $\begin{array}{l}\text { acetato de } \\
\text { bornila }\end{array}$ & $0,10-3,40$ & $1,19-14,32$ & $2,40-4,80$ & $1,10-6,00$ & $0,50-2,00$ & & \\
\hline timol & & $0,00-0,70$ & $0,00-1,20$ & & 0,50 & & \\
\hline
\end{tabular}

continua.... 
continuação

\begin{tabular}{|c|c|c|c|c|c|c|c|}
\hline \multirow[t]{2}{*}{ SUBST' NCIAS* } & \multicolumn{7}{|c|}{ PA"SES / N MERO DE AMOSTRAS } \\
\hline & Espanha /13 & Fran $a / 7$ & Iugosl/wia/5 & Hungria/3 & Portugal $/ 3$ & Bulg/Eia/1 & Grøia/1 \\
\hline carvacrol & & $0,00-0,14$ & $0,00-2,00$ & $1,00-3,50$ & $0,00-2,90$ & & \\
\hline copaeno & 0,05 & $\operatorname{tra} o$ & 0,30 & & 0,30 & & \\
\hline$\beta$-cariofileno & $0,90-3,09$ & $0,00-3,70$ & $2,90-9,70$ & $1,00-3,50$ & $0,00-2,90$ & & \\
\hline$\alpha$-humuleno & $0,26-1,15$ & $0,00-0,94$ & & & & & \\
\hline $\begin{array}{l}\text { xido de } \\
\text { cariofileno }\end{array}$ & $0,03-1,44$ & $0,00-0,10$ & & & & & \\
\hline epi- $\alpha$-bisabolol & & $0,00-0,27$ & & & & & \\
\hline $\begin{array}{l}\text { acetato de } \\
\text { linalila }\end{array}$ & 1,25 & $0,00-5,52$ & $0,00-0,22$ & & & & 0,80 \\
\hline $\begin{array}{l}\text { acetato de } \alpha \text { - } \\
\text { fenchila }\end{array}$ & & & 0,57 & & & & \\
\hline $\begin{array}{l}\text { acetato de } \\
\text { isobornila }\end{array}$ & & $0,90-0,90$ & $0,00-7,28$ & & & 1,40 & \\
\hline $\begin{array}{l}\text { acetato de } \alpha \text { - } \\
\text { terpinila }\end{array}$ & & & 12,76 & & & & \\
\hline rho-cimeno & $0,00-2,70$ & $0,20-2,70$ & 2,00 & & 3,70 & & \\
\hline$\delta$-3-careno & $0,07-0,19$ & & & & & & \\
\hline $\begin{array}{l}3,5,5- \\
\text { trimetilciclohex } \\
\text { anol }\end{array}$ & & $0,02-2,40$ & & & & & \\
\hline $\begin{array}{l}\text { Afcool } \alpha- \\
\text { fenquila }\end{array}$ & & $1,00-2,00$ & & & & & \\
\hline
\end{tabular}

* Apresentadas segundo ordem de eluição em coluna 5\% difenil/95\% dimetilpolissiloxano (SE-54).

Cânfora e 1,8-cineol são usados no tratamento de tosses e irritações inespecíficas do trato respiratório $(28,46)$. A inalação de cânfora ajuda, rapidamente, a pessoa desmaiada a recuperar a consciência. Este efeito é baseado na estimulação dos centros medulares, especialmente os centros da respiração e circulação via nervo olfatório $(28,46)$. O 1,8-cineol estimula a atividade motora em ratos após inalação, possivelmente por afetar os centros motores no cérebro. Também aumenta o fluxo sangüíneo e a atividade cortical tanto em mulheres saudáveis como anósmicas (27, 46). 


\section{TABELA 2 - COMPOSIÇÃO QUÍMICA PERCENTUAL DE ÓLEOS ESSENCIAIS DE $R$. officinalis ENCONTRADA EM OUTROS CONTINENTES $(13,34-44)$}

\begin{tabular}{|c|c|c|c|c|c|c|}
\hline \multirow[t]{3}{*}{ Subst ncias* } & \multicolumn{6}{|c|}{$\begin{array}{c}\text { Continentes } \\
\text { Pa ses / Nomero de Amostras }\end{array}$} \\
\hline & \multicolumn{3}{|c|}{ frica } & \multicolumn{2}{|c|}{ sia } & Am Ørica do \\
\hline & Egito / 4 & Tun sia $/ 1$ & Marrocos / 7 & China / 2 & Turquia / 4 & Argentina / 2 \\
\hline tricicleno & & & $0,10-0,23$ & & & \\
\hline$\alpha$-thujeno & $0,28-0,93$ & & tra os & & $0,27-0,43$ & $1,20-1,90$ \\
\hline$\alpha$-pineno & $2,46-36,40$ & $8,60-11,40$ & $9,56-12,72$ & 8,53 & $0,44-11,47$ & $7,90-10,90$ \\
\hline canfeno & $1,63-19,20$ & $2,70-4,30$ & $3,21-3,98$ & 2,21 & $3,81-9,25$ & $4,10-5,10$ \\
\hline sabineno & $0,00-6,40$ & & $0,14-0,21$ & & $0,00-0,44$ & \\
\hline$\beta$-pineno & $1,20-4,00$ & $2,70-7,70$ & $5,53-7,83$ & 3,66 & 0,44 & $2,10-4,80$ \\
\hline mirceno & $0,48-10,20$ & $1,10-1,30$ & $1,27-1,60$ & 0,39 & $0,38-1,90$ & $17,90-20,40$ \\
\hline$\alpha$-felandreno & $0,46-4,50$ & & & & 0,38 & \\
\hline$\alpha$-terpineno & $0,27-040$ & & $0,52-0,66$ & & 3,29 & $0,30-0,40$ \\
\hline$p$-cimeno & $1,77-11,35$ & $1,10-1,80$ & $0,99-1,40$ & 1,00 & 0,93-10,5 & \\
\hline limoneno & $2,52-7,08$ & $1,90-4,80$ & $1,86-2,06$ & & $0,82-1,75$ & $2,90-4,80$ \\
\hline 1,8-cineol & $8,96-19,20$ & $40,1-55,10$ & $43,53-53,48$ & 69,33 & $18,16-40,57$ & $14,50-15,30$ \\
\hline$\gamma$-terpineno & $0,09-0,26$ & & $0,93-1,19$ & & $0,52-1,52$ & \\
\hline cis-sabineno hidratado & 0,03 & & & & 1,93 & \\
\hline trans-sabineno hidratado & & & $0,04-0,19$ & & 1,44 & \\
\hline linalol & $5,44-6,60$ & $0,60-1,30$ & $0,73-1,76$ & 0,33 & $0,80-1,43$ & \\
\hline c nfora & $3,20-14,91$ & $6,40-14,80$ & $7,42-10,80$ & 7,25 & $7,63-23,06$ & $9,00-9,30$ \\
\hline borneol & $0,30-5,40$ & & $3,00-4,51$ & 1,71 & $5,63-17,50$ & $0,70-1,10$ \\
\hline 4-terpineol & $2,15-2,88$ & $0,60-1,60$ & $0,69-0,91$ & 0,28 & $1,18-3,63$ & \\
\hline terpinoleno & & & $0,29-0,36$ & & & 1,40 \\
\hline$\alpha$-terpineol & $1,20-4,92$ & & $0,00-2,46$ & 1,35 & $0,83-2,49$ & $0,80-1,10$ \\
\hline verbenona & $7,58-12,33$ & $\operatorname{tra} o$ & $0,00-0,40$ & & $0,93-15,58$ & $0,30-0,70$ \\
\hline acetato de bornila & $0,98-7,59$ & $0,40-1,20$ & $0,12-0,86$ & 0,83 & $0,75-3,85$ & $0,50-0,90$ \\
\hline timol & & & 0,90 & & 0,90 & \\
\hline carvacrol & $0,15-0,35$ & & & & 1,73 & \\
\hline copaeno & $0,09-0,14$ & & & & & \\
\hline$\beta$-cariofileno & $1,54-2,75$ & $0,90-1,10$ & $2,41-4,32$ & 1,69 & 1,22 & $4,40-8,30$ \\
\hline$\alpha$-humuleno & $0,33-0,83$ & & $0,27-5,43$ & 0,18 & $0,25-0,53$ & $1,60-2,90$ \\
\hline xido de cariofileno & $0,34-1,31$ & & $0,00-0,10$ & & & \\
\hline epi- $\alpha$-bisabolol & 0,20 & & & & & \\
\hline
\end{tabular}

continua... 
continuação

\begin{tabular}{|c|c|c|c|c|c|c|}
\hline \multirow[t]{3}{*}{ Subst ncias* } & \multicolumn{6}{|c|}{$\begin{array}{c}\text { Continentes } \\
\text { Pa ses / Nomero de Amostras }\end{array}$} \\
\hline & \multicolumn{3}{|c|}{ frica } & \multicolumn{2}{|c|}{ sia } & AmØica do \\
\hline & Egito / 4 & Tun sia /1 & Marrocos / 7 & China / 2 & Turquia / 4 & Argentina / 2 \\
\hline acetato de linalila & 1,40 & & $0,00-0,02$ & & & \\
\hline piperitona & $0,19-0,27$ & & & & 0,76 & \\
\hline geraniol & $0,10-0,68$ & & $0,00-0,05$ & & & \\
\hline$\alpha$-muuroleno & 0,17 & & $0,00-0,13$ & & & \\
\hline 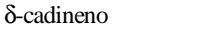 & $0,22-0,61$ & & $0,18-0,77$ & & & \\
\hline
\end{tabular}

* Apresentadas segundo ordem de eluição em coluna 5\% difenil/95\% dimetilpolissiloxano (SE-54).

O linalol, o $\alpha$-terpineol e o acetato de linalila decresceram a atividade motora de ratos entre 40 e $78 \%$, comparado com $0 \%$ do controle (27). Estas substâncias também exerceram ação inibitória no crescimento de 4 microrganismos (E. coli, L. monocytogenes, Salmonella typhimuriume Vibrius vulnificus), relacionada com a dose aplicada, sendo que a $1000 \mu \mathrm{g} / \mathrm{mL}$ inibiram completamente o crescimento de $E$. coli e $V$. vulnificus, mas não totalmente o de L. monocytogenes. Já o limoneno exerceu fraca ação inibitória no crescimento de V. vulnificus (26).

Os compostos aos quais podem ser atribuídas atividades antibacterianas na sálvia e alecrim são: borneol, 1,8-cineol, pineno, canfeno e cânfora (11). Não obstante, parece que a associação de componentes também é importante, e não apenas a dos componentes majoritários (12).

O óleo essencial puro de alecrim também exerce forte atividade espasmogênica in vitro em músculo liso de íleo de porquinhos-da-índia, existindo correlação positiva entre os níveis de $\alpha$ e $\beta$ pinenos, $p$-cimeno e limoneno e a ação espasmódica muscular. Também já foi observado em ratos o efeito espasmogênico do $\alpha$-pineno e do canfeno. Já o 1,8-cineol (teor de $50 \%$ no óleo essencial estudado) não apresentou correlação com a bioatividade do óleo essencial, pois enquanto o óleo essencial de alecrim é fortemente espasmogênico, o óleo essencial de Eucalyptus globulus Labill, com altos conteúdos de 1,8-cineol demonstrou desprezível atividade antiespasmódica (31). 
Quando testados individualmente, 1,8-cineol, borneol, $p$-cimeno, limoneno, mirceno, $\alpha$-pineno, $\beta$ pineno, $\alpha$-terpineno e o $\gamma$-terpineno apresentaram atividade espasmogênica, enquanto cariofileno, linalol, acetato de linalila e $\alpha$-terpineol foram espasmolíticos (31).

\section{CONSIDERAÇÕES FINAIS}

As atividades antimicrobiana e fisiológica do óleo essencial de alecrim são atribuídas ao efeito conjunto de diversas substâncias, sendo os compostos hidroxilados, carbonilados e os epóxidos apontados como os principais responsáveis.

Quanto à composição química do óleo essencial de alecrim existe acordo sobre os monoterpenos serem majoritários. Entretanto, mesmo que se considere os óleos provenientes dos países essencialmente produtores como padrões internacionais ainda há discrepância entre as principais substâncias (ora são hidrocarbonetos, como pinenos, mirceno, canfeno e ora são oxigenadas, como cânfora, 1,8-cineol e borneol).

O óleo essencial rico em determinados compostos será adequado para certo propósito. Por exemplo, o óleo rico em cânfora pode constituir bom agente antimicrobiano em alimentos, mas outro óleo rico em 1,8-cineol pode ser preferido para uso terapêutico. Por isso, determinar a composição química do óleo essencial é importante para aproveitar suas potencialidades e valorizá-lo comercialmente.

Apesar de cultivado em quase todo o território brasileiro e importado para o consumo interno, poucos estudos têm sido realizados sobre esta importante planta condimentar em nível nacional.

\section{Abstract}

ROSEMARY (Rosmarinus officinalis L.): ESSENTIAL OIL ANTIMICROBIAL AND CHEMICAL PROPERTIES

This article presents a brief review on the chemical composition and antimicrobial properties of the rosemary essential oil. It focuses general features, uses, antimicrobial activity against bacteria and fungi in foods and the major compounds of the rosemary oil from different countries. Concludes that physiologic and antimicrobial activities are due to oxygenated compounds, but there is discordance about the major components if hydrocarbon or oxygenated monoterpenes.

KEY-WORDS: ROSEMARY; ROSEMARY OIL; ANTIMICROBIAL PROPERTIES; CHEMICAL PROPERTIES; ESSENTIAL OIL. 


\section{REFERÊNCIAS}

1 EPLING, C.; TOLEDO, J.F. Flora brasílica. São Paulo: Graphicars, 1943. v. 48 , p. $16-18 ; 61-64$.

2 BRAGA, R. Plantas do nordeste, especialmente do Ceará. 2.ed. Fortaleza: Imprensa Oficial, 1960. p. 16, 439.

3 LOEWENFELD, C.; BACK, P. Guía de las hierbas y especias. Barcelona: Omega, 1978. p. 256-276.

4 SVOBODA, K.P.; DEANS, S.G. A study of the variability of rosemary and sage and their volatile oils on the British market: their antioxidative properties. Flavour and Flagrance Journal, v. 7, n. 2, p. 81-87, April 1992.

5 JOLY, A. B. Botânica: introdução à taxonomia vegetal. 3.ed. São Paulo: Nacional, 1976. v. 4, p. 571-586.

6 CRAVEIRO, A.A.; FERNANDES, A.G.; ANDRADE, C.H.S.; MATOS, F.J.A.; ALENCAR, J.W.; MACHADO, M.I.L. Óleos essenciais de plantas do nordeste. Fortaleza: UFC, 1981. p. 63.

7 BARROSO, G.M. Sistemática de angiospermas do Brasil. Viçosa: Universidade Federal de Viçosa, 1986. v. 3, p. 98-118.

8 GUILLÉN, M.D.; CABO, N.; BURILLO, J. Characterization of the essential oils of some cultivated aromatic plants of industrial interest. Journal of the Science of Food and Agriculture, v. 70, n. 3, p. 359-363, Mar. 1996.

9 HILL, A. F. Botánica económica: plantas útiles y productos vegetales. Barcelona: Omega, 1965. p. 26-523.

10 SPICES: Style. Food Product Development, v. 14, n. 8, p. 30-40, Aug. 1980.

11 SHELEF, L.A.; NAGLIK, O.A.; BOGEN, D.W. Sensitivity of some common food-borne bacteria to the spices sage, rosemary and allspice. Journal of Food Science, v. 45, n. 4, p. 1042-1044, Jul./Aug., 1980.

12 BENJILALI, B.; TANTAOUI-ELARAKI, A.; AYADI, A.; IHLAL, M. Method to study anti-microbial effects of essential oils: application to the antifungal activity of six Maroccan essences. Journal of Food Protection, v. 47, n. 10, p. 748-752, Oct., 1984.

13 SOLIMAN, F.M.; EL-KASHORY, E.A.; FATHY, M.M.; GONAID, M.H. Analysis and biological activity of the essential oil of Rosmarinus officinalis from 
Egypt. Flavour and Fragrance Journal, v. 9, n. 1, p. 29-33, Jan./Feb. 1994.

14 MEDSEN, H. L.; BERTELSEN, G. Spice as antioxidants. Trends in Food Science \& Technology, v. 6, n. 8, p. 271-277, Aug. 1995.

15 FARAG, R.S.; DAW, Z.Y.; ABO-RAYA, S.H. Influence of some spice essential oils on Aspergillus parasiticus growth and production of aflatoxins in a synthetic medium. Journal of Food Science, v. 54, n. 1, p. 74-76, Jan./ Feb. 1989.

16 SCHWARZ, K., TERNES, W. Antioxidative constituints of Rosmarinus officinalis and Salvia officinalis. I. Determination of phenolic diterpenes with antioxidative activity amongst tocochromanol using HPLC. Zeitschriftt für Lebensmittel-Untersuchung und-Forschung, v. 195, n. 2, p. 95-98, Aug. 1992a.

17 SCHWARZ, K.; TERNES, W. Antioxidative constituints of Rosmarinus officinalis and Salvia officinalis. II. Isolation of carnosic acid and formation of other phenolic diterpenes. Zeitschriftt für Lebensmittel-Untersuchung und-Forschung, v. 195, n. 2, p. 99-103, Aug. 1992b.

18 SCHWARZ, K.; TERNES, W.; SHMAUDERER, E. Antioxidative constituints of Rosmarinus officinalis and Salvia officinalis. III. Stability of phenolic diterpenes of rosemary extracts under thermal stress as requerid for technological processes. Zeitschriftt für Lebensmittel-Untersuchung und-Forschung, v. 195, n. 2, p. 104-107, Aug. 1992c.

19 WERKER, E. Function of essential oil-secreting glandular hairs in aromatic plants of the Lamiaceae: a review. Flavour and Fragrance Journal, v. 8, n. 5, p. 249-255, Sep./Oct., 1993.

20 MIRALLES, J. Distilled Labiatae oils from Spain. Perfumer \& Flavourist, v. 23, n. 3, p. 15-17, May/Jun., 1998.

21 SENA, K.X.F.R.; ANDRADE, M.S.A.S.; LIMA, R.C.; SANTOS, E.R. Atividades biológicas de Rosmarinus officinalis L. (R.Latifalius Mill). Boletim da Sociedade Broteriana, v. 66, p. 97-109, 1993.

22 COLLINS, M.A.; CHARLES, H.P. Antimicrobial activity of carnosol and ursolic acid: two antioxidants constituints of Rosmarinus officinalis. Food Microbiology, v. 4, n. 4, p. 311-315, Oct. 1987.

23 FARAG, R.S.; SALEM, H.; BADEI, A.Z.M.A.; HASSANEIN, D.E. Biochemical studies on the essential oils of some medicinal plants. Fette Seifen Anstrichmittel, v. 2, n. 2, p. 69-72, Feb. 1986.

24 OUATTARA, B.; SIMARD, R.E.; HOLLEY, R.A.; PIETTE, G.J.P.; BÉGIN, A. 
Antibacterial activity of selected fatty acids and essential oils against six meat spoilage organisms. International Journal of Food Microbiology, v. 37, n. 23, p. 155-162, Jul. 1997.

25 CHAIBI, A.; ABABOUCH, L.H.; BELASRI, K.; BOUCETTA, S.; BUSTA, F.F. Inhibition of germination and vegetative growth of Bacillus cereus $T$ and Clostridium botulinum $62 \mathrm{~A}$ spores by essential oils. Food Microbiology, v. 14, n. 2, p. 161-174, April 1997.

26 KIM, J.; MARSHALL, M.R., WEI, C. Antibacterial activity of some essential oil components against five foodborne pathogens. Journal of Agricultural and Food Chemistry, v. 43, n. 11, p. 2839-2845, Nov., 1995.

27 BUCHBAUER, G.; JIROVETZ, L. Aromatherapy: use of fragrances and essential oils as medicaments. Flavour and Fragrance Journal, v. 9, n. 5, p. 217-222, Sep./Oct. 1994.

28 ISMAIEL, A.; PIERSON, M.D. Inhibition of germination, outgrowth, and vegetative growth of Clostridium botulinum 67B by spice oils. Journal of Food Protection, v. 53, n. 9, p. 755-758, Sep. 1990.

29 WENDORFF, W. L., WEE, C. Effect of smoke and spice oils on growth of molds on oil-coated cheese. Journal of Food Protection, v. 60, n. 2, p. 153-166, Feb. 1997.

30 YIN, M., CHENG, W. Inhibition of Aspergillus niger and Aspergillus flavus by some herbs and spices. Journal of Food Protection, v. 61, n. 1, p. 123-125, 1998.

31 AKGÜL, A., KIVANÇ, M., SERT, S. Effect of carvacrol on growth of a toxin production by Aspergillus flavus and Aspergillus parasiticus. Sciences des Aliments, v. 11, n. 2, p. 361-370, April 1991.

32 FARAG, R.S.; DAW, Z.Y.; HEWEDI, F.M.; EL-BAROTY, G.S.A. Antimicrobial activity of some egyptium spice essential oils. Journal of Food Protection, v. 52, n. 9, p. 665-667, Sep., 1989.

33 LIS-BALCHIN, M.; HART, S.; DEANS, S. G.; EAGLESSHAM, E. Comparison of the pharmacological and antimicrobial action of commercial plant essential oils. Journal of Herbs, Spices \& Medicinal Plants, v. 4, n. 2, p. 69-86, Feb.,1996.

34 LAWRENCE, B. M. Progress in essential oils. Perfumer \& Flavourist, v. 7, n. 6, p. 22-25, Dec. 1982/Jan. 1983.

35 LAWRENCE, B.M. Progress in essential oils. Perfumer \& Flavourist, v. 9, n. 4, p. 41,43, Aug./Sep., 1984. 
36 LAWRENCE, B.M. Progress in essential oils. Perfumer \& Flavourist, v. 11, n. 2, p. 81-82, Apr./May. 1986.

37 LAWRENCE, B.M. Progress in essential oils. Perfumer \& Flavourist, v. 14, n. 2, p. 49-54, Mar./Apr. 1989.

38 LAWRENCE, B. M. Progress in essential oils. Perfumer \& Flavourist, v. 16, n. 2, p. 59-60, Mar./Apr. 1991.

39 LAWRENCE, B.M. Progress in essential oils. Perfumer \& Flavourist, v. 17, n. 6, p. 57-58, Nov./Dec. 1992.

40 LAWRENCE, B.M. Progress in essential oils. Perfumer \& Flavourist, v. 20, n. 1, p. 47-51, Jan./Feb. 1995.

41 LAWRENCE, B. M. Progress in essential oils. Perfumer \& Flavourist, v. 22, n. 5, p. 71-73, Sep./Oct. 1997.

42 TOMEI, P. E.; CIONI, P. L.; FLAMINI, G.; STEFANI, A. Evaluation of the chemical composition of the essential oils of some Lamiacea from Serrania de Ronda (Andaluçia, Spain). The Journal of Essential Oil Research, v. 7, n. 3, p. 279-282, May/Jun. 1995.

43 ADAMS, R. P. Identification of essential oil components by gas chromatography/mass spectroscopy. Wheaton, Illinois: Allured, 1995. $467 \mathrm{p}$.

44 PÉREZ-ALONSO, M.J.; VELASCO-NEGUERUELA, A.; EMINDURU, M.; HARMANDAR, M.; ESTEBAN, J.L.. Composition of the essential oil of Ocimum basilicum var. Glabratum and Rosmarinus officinalis from Turkey. The Journal of Essential Oil Research, v. 7, n. 1, p. 73-75, Jan./Feb. 1995.

45 BOUTEKEDJIRET, C.; BENTAHAR, F.; BELABBES, R. The essential oil from Rosmarinus officinalis L. in Algeria. The Journal of Essential Oil Research, v. 10, n. 6, p. 680-682, Nov./Dec. 1998.

46 BUCHBAUER, G. Aromatherapy: do essential oils have therapeutic properties? Perfumer \& Flavorist, v. 15, n. 3, p. 47-50, May/Jun. 1990. 